\title{
Endovascular treatment of true renal artery aneurysms: a single center experience
}

\section{Gonca Eldem (1) \\ Erhan Erdoğan \\ Bora Peynircioğlu \\ Anıl Arat \\ Ferhun Balkancı}

\begin{abstract}
PURPOSE
We aimed to report a single center's experience on endovascular treatment of true renal artery aneurysms (TRAAs), including treatment techniques and outcomes.
\end{abstract}

\section{METHODS}

This retrospective study was designed to evaluate the treatment and follow-up of TRAAs treated by a variety of endovascular interventional techniques over a period of 6 years. Six patients with nine TRAAs were identified; seven of the TRAAs were treated using different combinations of coil embolization and flow diverter stents. The clinical findings, aneurysm characteristics, endovascular methods and treatment outcomes were reported.

\section{RESULTS}

Seven TRAAs of six patients were treated, with a median aneurysm size of $20 \mathrm{~mm}$. Three TRAAs were treated with primary sac occlusion (one with primary coil embolization, one with balloon and stent assisted coil and glue embolization, and one with amplatzer vascular occlusion device and coil embolization). The remaining four TRAAs of three patients were treated with flow diverter stents (Cardiatis, Silk, Pipeline, and Surpass). Immediate clinical success was achieved in patients treated with primary sac embolization $(95 \% \mathrm{Cl}, 29.2 \%-100 \%)$. Among patients treated with flow diverter stents, one patient required an additional flow diverter at 6-month follow-up. The occlusion time in flow diverters ranged from 1 month to 12 months (median, 3.5 months) taking the repeat procedure into account. In patients treated with flow diverters, the clinical success rate was $100 \%(95 \% \mathrm{Cl}, 29.2 \%-100 \%)$ at one-year follow-up. Long-term follow-up ranged from 3 to 52 months. One intraprocedural complication was encountered with a flow diverter during deployment, which required additional stenting and tirofiban infusion. No other major complication was seen.

\section{CONCLUSION}

Endovascular treatment is an effective and safe method offering high success rates and low morbidity in the treatment of TRAAs and may supplant surgery as the primary therapy. Current experience in the use of flow diverter stents in TRAAs is limited to individual case reports with one brand of flow diverter device. Our small numbered series of four TRAAs shows our experience regarding endovascular treatment with different flow diverter brands.
From the Department of Radiology (G.E. $\square$ goncaeldem@gmail.com, B.P., A.A., F.B.), Hacettepe University School of Medicine, Ankara, Turkey; Department of Radiology (E.E.), Eskisehir Yunus Emre State Hospital, Eskişehir, Turkey.

Received 24 September 2017; revision requested 12 November 2017; last revision received 20 April 2018; accepted 2 May 2018.

Published online 28 September 2018.

DOI 10.5152/dir.2018.17354
$\mathrm{T}$ rue renal artery aneurysms (TRAAs) are rare entities with an incidence of $0.01 \%$ $0.09 \%$ in general autopsy series (1). They represent $22 \%-25 \%$ of visceral arterial aneurysms and their incidence ranges $0.3 \%-2.5 \%$ upon angiographic and computerized tomography studies (2-5). Risk factors associated with the development of TRAAs are fibromuscular dysplasia, atherosclerosis, and vasculitis such as Marfan syndrome, Takayasu, or Behcet disease (6). In common with true arterial aneurysms, they are characterized as localized dilatation of the arterial wall consisting of all three layers. Indications for treatment include diameter size $>2 \mathrm{~cm}$, symptoms such as pain, rupture, hematuria or hypertension and women who are pregnant or of childbearing age $(7,8)$.

Currently treatment strategies of TRAAs favor endovascular approaches because of their high technical and clinical success rates, minimal invasiveness and shorter hospital stay (9). Among different endovascular treatment options the treatment choice is made upon the 


\begin{tabular}{|c|c|c|c|c|c|c|}
\hline 2 & $43 / F$ & Incidental & Right extra renal bifurcation & $18 / 10$ & 2 & $\begin{array}{l}\text { Splenic aneurysms }<1 \mathrm{~cm} \\
\text { Findings of FMD }\end{array}$ \\
\hline 4 & $42 / F$ & FMD, hypertension & Right extra renal bifurcation & $20 / 10$ & 2 & $\begin{array}{l}\text { Findings of FMD on the } \\
\text { main renal artery }\end{array}$ \\
\hline $5^{a}$ & $41 / \mathrm{M}$ & Abdominal pain & $\begin{array}{l}\text { Left intrarenal anterior } \\
\text { division }\end{array}$ & $25 / 7$ & None & None \\
\hline
\end{tabular}

anatomical characteristics of the aneurysm and the operator's experience. The purpose of treatment is to exclude flow into the aneurysm, thus preventing growth and rupture while maintaining normal blood flow to the renal parenchyma. Different techniques with coil embolization, stent grafts, and onyx embolization have been reported although the outcome data following endovascular treatment still remains limited to case series $(7,9,10)$. The objective of our study was to examine our institution's experience, technical and clinical outcomes in patients with TRAAs treated with coil embolization and flow diverting stents.

\section{Main points}

- True renal artery aneurysms (TRAAs) are rare entities; endovascular treatments of TRAAs are effective and safe, trending to supplant surgery.

- The choice of endovascular technique should be made case by case, based on aneurysm characteristics, patient's vasculature, and operator experience.

- Flow diverter stents can be used as alternatives, particularly in wide-neck complex aneurysms with efferent branches; however, technical deployment difficulties and therapeutic outcomes should be kept in mind when choosing this strategy. Modification of intracranial designs for peripheral use or dedicated designs of flow diverters for visceral/renal arteries are still needed.

\section{Methods}

Local ethics committee approval was obtained for this retrospective study. Patients undergoing endovascular treatment for renal aneurysms from January 2009 through May 2016 were retrospectively searched from our institution's database. Patients with pseudoaneurysms, arteriovenous fistula, multiple microaneurysms and aberrant vascularity related to angiomyolipoma or other renal tumors were excluded and six patients with nine TRAAs were included in the study. Parameters regarding (1) patient demographics, symptoms, etiology; (2) aneurysm characteristics, size, location, number of efferent branches, presence of additional renal artery pathology; (3) endovascular treatment technique; (4) technical and clinical success and complications were recorded. Technical success was described as exclusion of the aneurysm from renal blood flow or successful deployment of the flow diverter stents. Clinical success was described as disappearance of symptoms in symptomatic cases or insignificant recanalization of the aneurysm treated with coil embolization and size decrement or occlusion of the aneurysmal sac treated with flow diverters. Binomial confidence intervals with logit parameterization were calculated using 'binom' package in R software. Complications were evaluated according to the Society of Interventional Radiology Standards of Practice Committee classification (11).
Endovascular treatment and indications

Endovascular treatment indications included size $(>2 \mathrm{~cm})$ in asymptomatic patients and hypertension, localized symptoms (flank pain, hematuria), distal embolization, female gender within childbearing age in patients with $<2 \mathrm{~cm}$ aneurysms. All patients underwent endovascular treatment within our interventional radiology suite under conscious sedation via femoral or brachial artery approach.

\section{Results}

Nine TRAAs were identified in six patients (4 male, 2 female). The median age of the study group was 41.5 years (range, 13-57 years). Three patients were asymptomatic, two patient presented with hypertension and one patient presented with abdominal pain and was diagnosed with TRAA during urolithiasis work-up. The diagnosis was made with computer tomography angiography (CTA) in three patients, magnetic resonance angiography in one patient and digital subtraction angiography (DSA) in two patients.

Table 1 presents aneurysm characteristics of patients. All nine TRAAS were saccular; six of them were located on the right renal artery and three of them on the left. These three left-sided aneurysms belonged to one patient and two of them were $<1 \mathrm{~cm}$ aneurysms, which were not treated due to size. One patient had two aneurysms on the same side, which were both treated. Thus, in total seven of nine TRAAs were treated. 


\begin{tabular}{|c|c|c|c|c|c|c|}
\hline 3 & $\begin{array}{l}\text { Primary coil and AVP } \\
\text { embolization }\end{array}$ & $\mathrm{RFA}+\mathrm{LBA}$ & $\begin{array}{l}\text { Anterior division arteries } \\
\text { sacrificed }\end{array}$ & None & Immediate & 3 \\
\hline 5 & Primary coil embolization & RFA & None & None & Immediate & 12 \\
\hline $6^{\mathrm{a}}$ & Pipeline 4-25 mm & RFA & $\begin{array}{l}\text { Protrusion of the diverter } \\
\text { into the main trunk } \\
\text { compromising the flow } \\
\text { to the other division; } \\
\text { (buttressed with Cobalt } \\
4-9 \mathrm{~mm} \text { stent+tirofiban } \\
\text { infusion) }\end{array}$ & $\begin{array}{l}4 \mathrm{~mm} \text { balloon } \\
\text { dilatation to the } \\
\text { proximal stent } \\
\text { due to relapsing } \\
\text { hypertension at } \\
\text { 1-month follow-up } \\
\text { Residual } 30 \%-50 \% \\
\text { stenosis left on the } \\
\text { posterior division } \\
\text { artery }\end{array}$ & $\begin{array}{l}\text { At 1-month } \\
\text { follow-up }\end{array}$ & 52 \\
\hline
\end{tabular}

RFA, right femoral artery; LBA, left brachial artery; AVP, amplatzer vascular occlusion device.

a Patient 6 had two aneurysms which were located side by side on the same branch ( $15 \mathrm{~mm}$ and $3 \mathrm{~mm}$ ) and both were covered with the same flow diverter
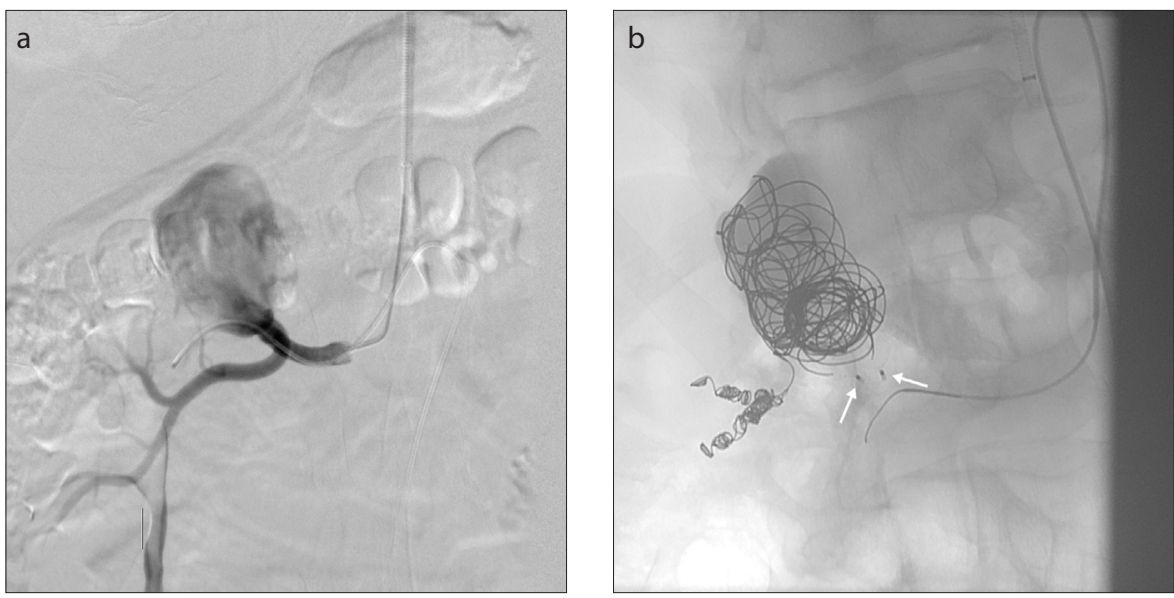

Figure 1. a, b. Angiography images of Patient 3. Note the giant aneurysm before (a) and after (b) embolization with coils and amplatzer vascular plugs (arrows).

The median diameter of the treated aneurysms was $20 \mathrm{~mm}$ (range, $5-55 \mathrm{~mm}$ ). The median neck size of the treated aneurysms was $8 \mathrm{~mm}$ (range, 3-12 $\mathrm{mm}$ ).

The locations of the seven treated TRAAs were on the renal artery trunk proximal to the bifurcation $(n=1)$, extrarenal on the bifurcation $(n=2)$, extrarenal distal to the bifurcation point $(n=3)$, and intrarenal on the branches distal to renal artery bifurcation $(n=1)$. In one patient the aneurysm had three efferent branches arising from the an- eurysmal sac and in two other patients two efferent branches were arising from the aneurysmal sac.

Endovascular treatment details are presented in Table 2. Seven TRAAs of six patients were treated with endovascular approaches by the same interventional team under conscious sedation. Brachial artery in two patients and femoral artery in three patients was preferred as the access site, whereas in one patient due to tortuous angulation both brachial and femoral approaches were needed as the access site.

Three TRAAs were treated with primary sac occlusion: one with primary coil embolization, one with balloon and stent assisted coil and glue embolization, and one giant aneurysm with amplatzer vascular occlusion device (AVP) and coil embolization. The remaining four aneurysms of three patients were treated with flow diverter stents. Two of these three patients had efferent main division branches arising from the sac and the other 


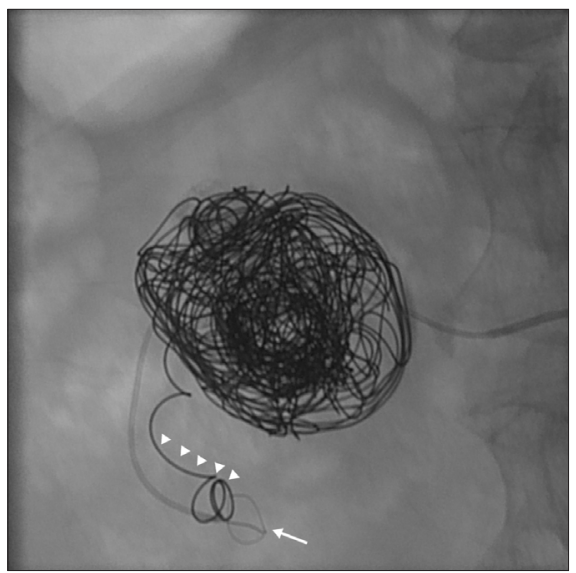

Figure 2. Snaring (white arrow) of the protruded coil (arrowheads) in Patient 1, who was treated with balloon + stent-assisted coil and glue embolization.

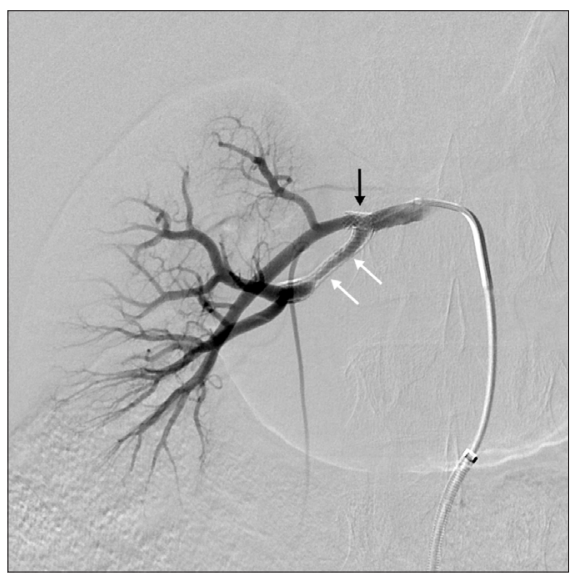

Figure 3. Angiographic follow-up and post balloon angioplasty image of Patient 6 , who had two TRAAs side by side, treated with Pipeline flow diverter (white arrows). The flow diverter protruded into the main renal artery risking the anterior branch and was therefore buttressed with an additional balloon expandable stent (black arrow). Balloon angioplasty was performed only into the proximal balloonmounted stent. The image also shows in-stent stenosis in the flow diverter (white arrows) which was not treated as access to the posterior division artery was not possible because of the balloon-mounted stent. The patient's hypertension was resolved after angioplasty to the proximal stent.

patient's two aneurysms had wide necks that disabled primary coil embolization.

Primary coil embolization was performed with 0.010-0.018-inch detachable coils through 2.5-2.8 F micro catheters via direct catheterization of the aneurysmal sac. In one patient the distal efferent branches were sacrificed with coiling as in the angiogram hypoperfusion and sluggish flow was seen in these arteries due to compression of the giant aneurysm, which was treated with AVP and coil embolization (Patient 3, Fig. 1). In one patient treated with balloon and stent assisted coil embolization, protrusion of one coil into the parent artery was observed and it was removed with a microsnare from the parent artery at the same session (Patient 1, Fig. 2).

The renal arteries of the patients treated with flow diverters were catheterized with long 6-7 F sheaths and flow diverter stents were deployed covering the neck of the aneurysms. All patients treated with flow diverters were anticoagulated with heparin during the procedure. In one patient, during deployment the flow diverter, stent's proximal part protruded into the main renal artery compromising the anterior branch. The anterior branch was catheterized and tirofiban infusion was performed and an additional balloon expandable stent was deployed to the proximal renal artery to buttress the flow diverter (Patient 6, Fig. 3).

In one patient, concurrent stenotic findings of fibromuscular dysplasia (FMD) was observed on the main renal artery and was treated with balloon angioplasty.

The median duration of hospitalization was 1 day (range, 1-3 days). Clinical and laboratory values were checked at one-month post-treatment; imaging (CTA or MRA) follow-up was performed at 6th and 12th months and on a yearly basis from then on. The need for control DSA was decided on case by case basis. One patient was lost to follow-up after 3 months. The range of follow-up in the study was 3-52 months. All patients treated with flow diverter stents were administered with antiplatelet treatment with clopidogrel and acetylsalicylic acid at least for 6 months.

Technical success rate was 100\% (95\% $\mathrm{Cl}, 29.2 \%-100 \%)$ in TRAAs treated with coil embolization and immediate occlusion were seen in the sacs. Among the three patients treated with the flow diverters, the patient whose flow diverter stent prolapsed into the division artery during deployment was considered as technical failure although it was managed with an additional stent (Patient 6). This patient had two sideby-side aneurysms and the patient showed signs of relapsing hypertension on the first month follow-up. A follow-up DSA was done and it showed occlusion of the aneurysmal sacs (covered by the flow diverter) but also stenosis in the proximal balloon mounted stent causing decreased flow on the main renal artery. A balloon angioplasty was done in the proximal stent reconstructing the normal flow pattern which relieved the patient's hypertension (Patient 6, Fig. 3). Even though no complication was encountered, the other two aneurysms treated by flow diverters showed occlusion in the first month. One patient needed reintervention at the 6-month follow-up as the aneurysm sac demonstrated filling without development of any thrombi in it (Patient 4, Fig. 4a-4d). Selective catheterization through the struts of the flow diverter stent for coil embolization failed; therefore a second flow diverter stent was deployed into the existing one (Patient 4, Fig. 4e, 4f). The sac showed occlusion 6 months after the second intervention with two efferent branches remaining intact at 18 months follow-up. The remaining third patient treated with a flow diverter showed a focal area of infarction of the upper pole covering $<20 \%$ of the renal parenchyma on first month CTA. At 6-month follow-up, no increase in the infarcted area was observed with occlusion of the aneurysmal sac only with minimal residual neck flow. This aneurysm was a complex wide-neck aneurysm with two efferent branches. During treatment technically the flow diverter was deployed through the larger efferent branch and it did not cover the other efferent branch (4 $\mathrm{mm}$ in diameter) rising from the sac. Right after deployment no occlusion was seen in either branch. When CT images were carefully evaluated it was observed that this jailed efferent branch rising from the sac remained partially intact with a reduced diameter and a distal subsegmental branch (with a diameter of $2 \mathrm{~mm}$ on angiographic images) rising from this efferent branch was occluded causing the infarcted area (Patient 2, Fig. 5). The patient showed no symptoms of pain or hypertension despite the infarcted area and occluded distal subsegmental branch. The median occlusion time in four aneurysms treated with flow diverter stents was calculated as 3.5 months (range, 1-12 months). Complete clinical success was achieved at one-year follow-up in all three patients $(95 \% \mathrm{Cl}, 29.2 \%-100 \%)$ treated with flow diverter stents, with the contribution of repeat procedures. Among patients treated with flow diverters intimal hyperplasia was seen in one patient only; however, the other two patients were evaluated with CTA.

There were no cases of conversion into open nephrectomy or rupture. No 30-day or overall mortality was observed. None 

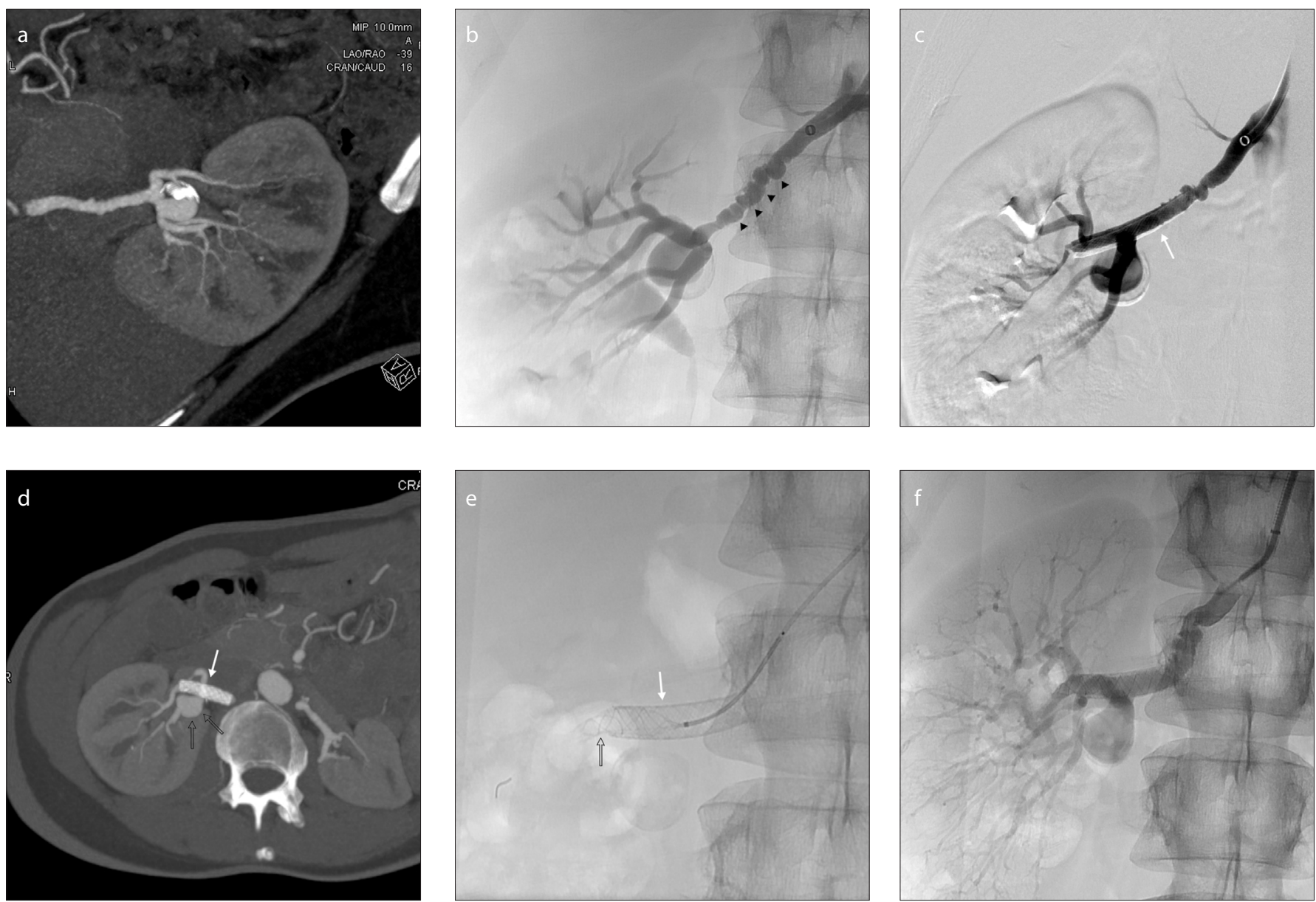

Figure 4. a-f. Panel (a) shows CTA MIP images of Patient 4. DSA image (b) of the same patient shows the findings of FMD (arrowheads) additional to the aneurysm. Post-treatment angiographic image (c) shows the Cardiatis flow diverter (white arrow) covering the aneurysm. Six-month follow-up CTA image (d) shows the Cardiatis flow diverter (white arrow); despite the treatment, the aneurysm sac is still filling without any thrombi in it (open arrows). Angiographic images of the second intervention of Patient $4(e, f)$ show the second flow diverter stent Silk (open arrow) into the first one.

of the patients showed deterioration in renal functions and creatinine levels remained within normal ranges through the follow-ups. Two patients described pain on the flank area which was relieved with oral analgesics without causing prolongation of the hospital stay. According to the Society of Interventional Radiology Standards of Practice Committee classification, the patient whose flow diverter protruded in the main renal artery (Patient 6) was considered to have a grade $\mathrm{C}$ complication. Although the branch occlusion was managed successfully with tirofiban infusion, it prolonged the hospital stay.

\section{Discussion}

TRAAs are rare and their natural history is not fully understood. Studies showing a higher prevalence in the female population are mostly attributed to $\operatorname{FMD}(12,13)$; however, of the three patients with accompanying FMD, only one was female, yield- ing a male predominance of $66.7 \%(95 \% \mathrm{Cl}$ : $27.2 \%-92.9 \%$ ) in our study, in parallel with the study by Tham et al. (2).

Indications for treatment include size exceeding $2 \mathrm{~cm}$ or evidence of progression (14-17). Smaller $(<2 \mathrm{~cm})$ but symptomatic TRAAs related with hypertension, hemorrhage, hematuria, flank pain should also be treated. Women who are pregnant or of childbearing age, dissecting aneurysms causing stenosis, intrarenal thromboemboli or infarction, patients with single kidney are other supplementary indications for treatment $(9,14,16,18)$. In our study, three patients were asymptomatic with sac diameters exceeding $2 \mathrm{~cm}$ in two of them. The remaining three patients were symptomatic, two of them presenting with hypertension and one with abdominal pain.

TRAAs are characterized by focal increase in the diameter of the renal artery or its branches containing all three vascular layers in their wall. Rundback et al. (16) pro- posed an angiographic classification dividing TRAAs into three categories. According to this, saccular aneurysms arising from the main renal artery or proximally from a large segmental branch are classified as type 1 . Fusiform aneurysms occurring at the main renal artery or proximal segmental branch are considered type 2 . Intralobar aneurysms arising from small segmental arteries or accessory arteries are classified as type 3 . In our study population, all seven aneurysms were saccular. Up to $10 \%-20 \%$ of cases renal artery aneurysms are bilateral and 7\%$30 \%$ of cases are associated with aneurysms in other arteries (13). Two of our patients (33\%) had multiple renal aneurysms and one patient (16\%) had associated splenic artery aneurysms; however, no bilateral case was seen.

Open surgical repair has been the traditional standard of care; however, endovascular treatment techniques have proven to be effective with no difference between 

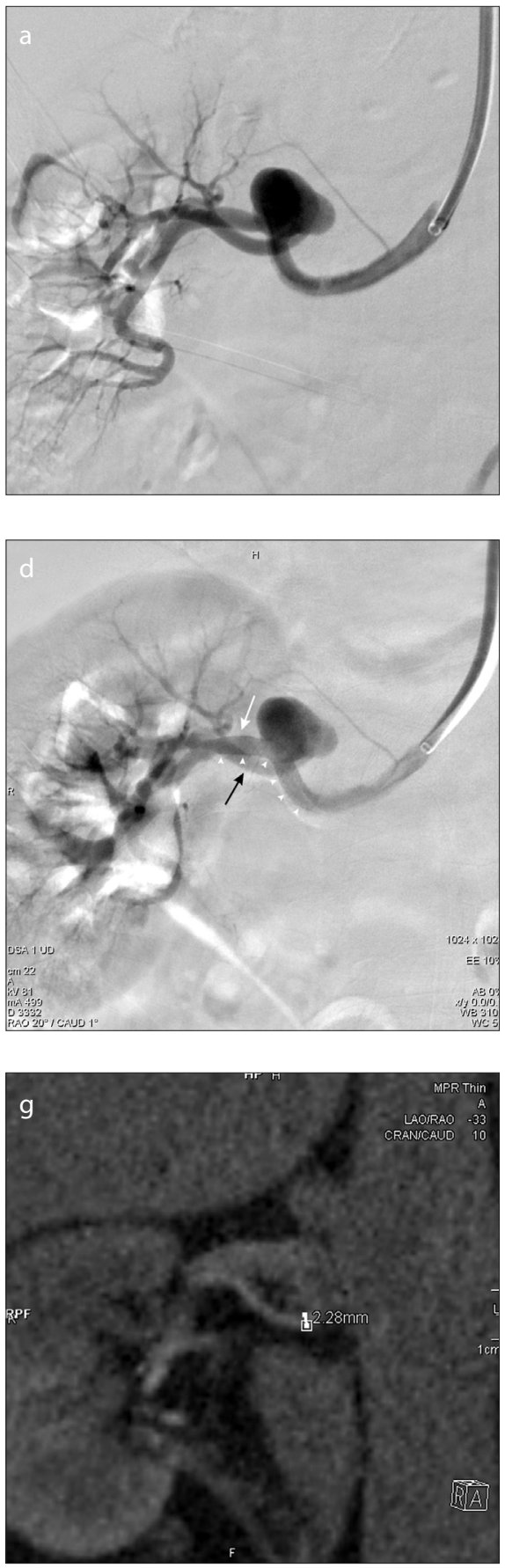

perioperative morbidity and mortality (19). Some studies have shown that endovascular treatment methods have the advantage of lower incidence of complications and a shorter hospital stay (19-21). In our study the average hospital stay was 1.3 days (range, 1-3 days) which is in parallel with the literature.

Several endovascular techniques have been described to treat TRAAs $(12,14,17$, 22-27). The choice depends on the anatomical characteristics of the aneurysm, vascular
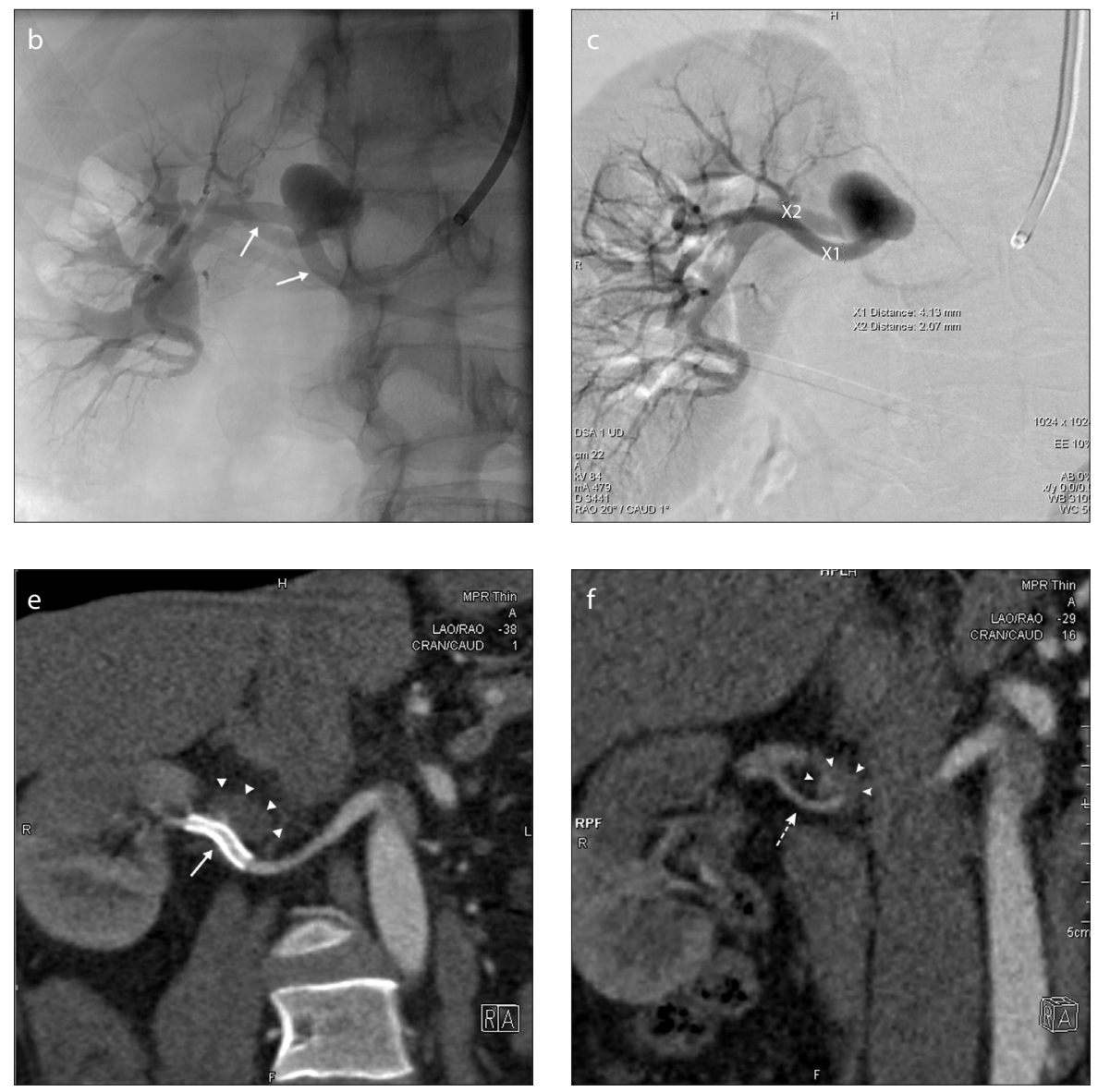

Figure 5. a-g. Angiographic images of Patient 2, who had a wide-neck aneurysm with efferent branches (a) treated with Surpass flow diverter (b, white arrows; $\mathbf{d}$, arrowheads). Note the diameter of the smaller efferent branch rising from the sac (c, X1; d, black arrow) and its distal subsegmental branch (c, X2) before deployment of the flow diverter. After deployment of the flow diverter (d, arrowheads), both of the efferent branches and also the distal subsegmental branches remained intact $(\mathbf{d}$, black arrow shows the jailed efferent branch and white arrow shows the efferent branch covered with the flow diverter). Six-month follow-up CTA images $(\mathbf{e}-\mathbf{g})$ show the patent flow diverter (e, white arrow) and thrombosis in the aneurysmal sac (e, $\mathbf{f}$, arrowheads). Note the jailed efferent branch (f, dashed arrow) is still intact, but with a smaller diameter (g).

anatomy of the patient, operator experience, and available technology (10). The shape, size, neck length, and location of the aneurysm, presence of efferent vascular branches arising from the sac, arterial anatomy of the parent artery and concomitant renal arterial disease are the determinants affecting endovascular treatment strategy $(7,10)$.

Saccular aneurysms with a narrow neck (neck length $<4 \mathrm{~mm}$, or sac-to-neck ratio $>2$ ) are suitable candidates for primary sac embolization with coils or liquid embolic agents $(7,12,28)$. In our study two aneurysms with narrow necks were treated with primary coil embolization.

Saccular aneurysms with a wide neck are more suitable for remodeling techniques such as balloon-assisted or stent-assisted coil embolization $(6,29)$; studies with balloon-assisted liquid embolic agents have also been described in the literature $(7,28$, 30-32). In our study one saccular aneurysm with a wide neck was treated with stent and balloon-assisted coil and glue embolization. 
Covered stent grafts have been described for the treatment of aneurysms arising from the main renal artery. However, they cannot be used in bifurcations and the length of the renal artery and presence of atherosclerosis often precludes this technique (33). Landing zone requirement of $15 \mathrm{~mm}$ and stiffness of the delivery system are also other limitations of this technique in visceral arteries. Long-term patency is another issue that needs to be concerned as covered stent graft occlusion is reported with an incidence of $17 \%$ (34-36).

Complex wide-neck aneurysms in proximity to or involving major efferent branches used to require extracorporeal arterial reconstruction and auto-transplantation. Recently, waffle-cone technique, a neurointerventional technique where distal end of a self-expandable stent is placed into the base of the aneurysm and coiled through it, has been successfully implemented on a patient with a wide-neck complex bifurcation renal artery aneurysm (37). However, this alternative for stent-assisted coiling is applied only in one case and needs further studies to confirm its efficacy and longterm results.

Latest technology in endovascular techniques now involves flow diverter stents. These are multilayered stents, specifically designed to reduce flow velocities in the aneurysm sac, promote thrombosis and maintain flow in the main artery and branch vessels. Although they are widely used in the neurovascular field, their use in the peripheral vascular system are still to be proven and so far their use in TRAAs are limited to a few case reports and short series (38-40). So far, in the English literature the flow diverters used in visceral arteries include the Pipeline Embolization Device (PED, ev3), the SILK Arterial Reconstruction Device (Balt Extrusion), and the Cardiatis Multilayer Stent (Cardiatis) (41).

Cases published in the English literature in the treatment of TRAAs have so far been only with the Cardiatis peripheral multilayer stent $(38,39,41,42)$. Other available flow diverters have been used in one splenic artery aneurysm (Pipeline) (43) and in one superior mesenteric artery aneurysm (SILK) (44).

In our study, four aneurysms in three patients were treated with flow diverters. Our choice on the flow diverters was determined by commercial availability at the time of treatment. Technical deployment of the flow diverters were nonproblematic, except
Pipeline. The patient treated with Pipeline required an additional proximal bare stent as the proximal part of the flow diverter outstretched into the main renal artery. One of the main considerations in the use of flow diverters is that they all have different deployment mechanisms. Even within the same brand there are different opinions on how to deploy them. This can be quite challenging during endovascular treatment, especially if the operator does not have sufficient neurointerventional experience.

Cases published in the English literature treated with Cardiatis multilayer stent showed occlusion within a range of 1-6 months $(38,39,41,42)$. However, in our study the patient treated with Cardiatis showed no occlusion in the sac at 6-month follow-up; therefore an additional intervention was performed and a second flow diverter (SILK) was deployed into the first one. Total occlusion was observed at 12-month follow-up total. Although from other studies it is known that occlusion rates can range up to 12 months, our patient showed no sign of thrombosis with sac diameter remaining the same as previous to the procedure. Therefore an additional intervention was decided.

Our Patient 3 is the first patient in the English literature who had a new generation flow diverter the Surpass flow diverter stent (Surpass; Stryker Neurovascular) placed for a renal artery aneurysm. At one-month CT imaging, an area of infarction of the upper pole covering $<20 \%$ of the renal parenchyma was observed and at 6-month follow-up the sac was occluded. This aneurysm was a complex wide-neck aneurysm with two efferent branches. Technically the flow diverter was deployed through the larger efferent branch and it did not cover the other efferent branch rising from the sac (so called jailed branch in neurointervention literature). Therefore this branch was anticipated to be occluded during follow-up although it was patent right after the stent deployment. However, it was observed that this jailed efferent branch rising from the sac remained partially intact with a reduced diameter and a distal subsegmental branch rising from this efferent branch was occluded causing the infarcted area. Many studies have been conducted in the neurointervention literature about the side branches. Bhogal et al. (45) showed occlusion rates of $5.3 \%$ and $42.6 \%$ in the ophthalmic and posterior communicating arteries, respective- ly. They also showed reduced flow and/or vessel caliber after flow diverter placement with a rate of $8.3 \%$ in the ophthalmic arteries and $6.4 \%$ in the posterior communicating arteries. It is believed that occlusion of covered branches is the result of the presence of distal collaterals and the suction effect created by lower pressure in these vessels. In the presence of collateral flow, a flow equalization point may occur, which results in the slow flow and occlusion of the proximal vessel proximal to the collaterals $(45,46)$. On the other hand, there are studies showing intact anterior choroidal arteries after flow diverter placement. Factors likely associated with side branch occlusion include the number of flow diverters covering the branch, the flow demand on that branch, and potential collateral circulation (47). In our case, the mechanism related with distal collaterals does not explain the occlusion of the subsegmental artery and/ or reduced vessel diameter of the jailed efferent branch, as renal arteries are distal end arteries without any significant collateral supply. The flow demand on that branch might explain our case as the efferent branch had a diameter of $4 \mathrm{~mm}$ and the subsegmental artery had a diameter of $2 \mathrm{~mm}$ and the renal area they supplied was very small, which may have not been enough to sump blood from across the flow diverter.

Another theory that can explain our case may be an emboli derived from the thrombosing aneurysmal sac occluding this small (2 $\mathrm{mm}$ ) subsegmental branch. Rouchaud et al. (48) showed that in patients with the ophthalmic artery arising from the aneurysm sac, $80 \%$ of patients developed new clinical visual symptoms and this was believed to be because of small retinal emboli derived from the thrombosing aneurysmal sac and traveling down the patent ophthalmic artery. We believe this theory is more likely to explain our case.

Another study comparing the flow diversion with and without occlusion of the jailed branch in 14 wide-neck aneurysms induced in eight canines showed that occlusion of the jailed branch resulted in better occlusion rates of aneurysmal occlusion, whereas patent aneurysms were associated with less dense neointimal coverage and persistent holes in the neointima (49). The investigators of this study suggested that occlusion of the side branch assists in the occlusion of aneurysms at bifurcations. Although in our case 
the proximal efferent jailed branch remained partially intact, we believe that the decrease in the vessel caliber and flow might have assisted aneurysmal occlusion (49).

At one-year follow-up the clinical success rate was $100 \%$ for the patients treated with flow diverters. Although small, this is the largest series of TRAA treated with flow diverting stents published in the English literature and the first case of a visceral artery treated with the new flow diverter Surpass. Although flow diverters are promising, especially in wide-neck complex aneurysms, when compared to surgery, one should keep in mind that the available flow diverters were designed for the neurovascular field and deployment mechanisms can be a challenge during the procedures. Dedicated designs for renal arteries or visceral arteries are needed. Also the fate of the side branches and their outcomes are yet to be shown when flow diverters are used in the peripheral system. The limitation of flow diverters are that they can cause stenosis themselves, therefore double antiplatalet treatment is required. This should be considered when treating young patients. In our cases, instent stenosis was seen in one patient only. Although the other two patients treated with flow diverters were followed with cross-sectional imaging they showed no in-stent stenosis at their last follow-up. Another limitation is that stents adjacent to bifurcations may prevent reconstructive surgery if needed in the future.

No bleeding complications, open nephrectomy or periprocedural mortality was seen in any of our patients, in parallel with the literature.

Limitations of our study are its retrospective design and restrictive number of patients. Also none of the aneurysms could be compared with surgery.

In conclusion, endovascular treatment of TRAAs is safe, effective and is a true alternative to surgical approaches. All endovascular techniques described in the literature have their own pros and cons and the choice should be made case by case, depending mainly on the aneurysm characteristics, patient's vasculature, and operator's experience. Flow diverters are promising alternatives for complex aneurysms with wide necks and efferent branches although further multicentered prospective randomized trials are needed, as little is known in the usage of flow diverters in the visceral vessels.
Conflict of interest disclosure

The authors declared no conflicts of interest.

\section{References}

1. Martin RS, Meacham PW, Ditesheim JA, et al. Renal artery aneurysms: selective treatment of hypertension and prevention of rupture. J Vasc Surg 1989; 9:26-34. [CrossRef]

2. Tham G, Ekelund L, Herrlin K, et al. Renal artery aneurysms natural history and prognosis. Ann Surg 1983; 197:348-352. [CrossRef]

3. Henriksson C, Lukes P, Nilson AE. Angiographically discovered, non- operated renal artery aneurysms. Scand J Urol Neprol 1984; 18:59-62. [CrossRef]

4. Zhang LJ, Yang GF, Qi J, Shen W. Renal artery aneurysm: diagnosis and surveillance with multidetector -row computed tomography. Acta Radiol 2007; 48:274-279. [CrossRef]

5. Deterling RA Jr. Aneurysm of the visceral arteries. J Cardiovasc Surg (Torino) 1971; 12:309-322.

6. Sedat J, Chau Y, Baque J. Endovascular treatment of renal aneurysms:a series of 18 cases. Eur J Radiol 2012; 81:3973-3978. [CrossRef]

7. Chung R, Touska P, Morgan R, Belli AM. Endovascular management of true renal arterial aneurysms: results from a single centre. Cardiovasc Intervent Radiol 2016; 39:36-43. [CrossRef]

8. Belli AM, Markose G, Morgan R. The role of interventional radiology in the treatment of abdominal visceral artery aneuryms. Cardiovasc Intervent Radiol 2012; 35:234-243. [CrossRef]

9. Etezadi V, Gandhi RT, Beneati JF, et al. Endovascular treatment of visceral and renal artery aneurysms. J Vasc Interv Radiol 2011; 22:1246-1253. [CrossRef]

10. Elaasar $\mathrm{O}$, Auriol J, Marquez R, Tall P, Rousseau $H$, Joffre $F$. Endovascular techniques for the treatment of renal artery aneurysms. Cardiovasc Intervent Radiol 2011; 34:926-935. [CrossRef]

11. Sacks D, McClenny TE, Cardella JF, Lewis CA. Society of Interventional Radiology clinical practice guidelines. J Vasc Interv Radiol 2003; 14:S199-S202. [CrossRef]

12. Nosher JL, Chung J, Brevetti LS, Graham AM, Siegel RL. Visceral and renal artery aneurysms: a pictorial essay on endovascular therapy. Radiographics 2006; 26:1687-1704. [CrossRef]

13. Coleman DM, Stanler JC. Renal artery aneurysms. J Vasc Surg 2015; 62:779-785. [CrossRef]

14. Pershad A, Heuser R. Renal artery aneurysm: successful exclusion with a stent graft. Catheter Cardiovasc Interv 2004; 61:314-316. [CrossRef]

15. Lacombe M. Aneurysms of the renal artery. J Mal Vasc 1995; 20:257-263.

16. Rundback JH, Rizvi A, Rozenblit GN, et al. Percutaneous stent-graft management of renal artery aneurysms. J Vasc Interv Radiol 2000; 11:1189-1193. [CrossRef]

17. Andersen $\mathrm{PE}$, Rohr N. Endovascular exclusion of renal artery aneurysm. Cardiovasc Intervent Radiol 2005; 28:665-667. [CrossRef]

18. Wayne EJ, Edwards MS, Stafford JM, Hansen KJ, Corriere MA. Anatomic characteristics and natural history of renal artery aneurysms during longitudinal imaging surveillance. J Vasc Surg 2014; 60:448-452. [CrossRef]
19. Tsilimparis N, Reeves JG, Dayama A, Perez SD, Debus ES, Ricotta JJ. Endovascular vs open repair of renal artery aneurysms: outcomes of repair and long term renal function. J Am Coll Surg 2013; 217:263-269. [CrossRef]

20. Hislop SJ, Patel SA, Abt PL, Singh MJ, Illig KA. Therapy of renal artery aneurysms in New York State: outcomes of patients undergoing open and endovascular repair. Ann Vasc Surg 2009; 23:194-200. [CrossRef]

21. Abdalla $S$, Pierret $C, B a B$, Mlynski A, de Kerangal $X$, Houlgatte $A$. Surgical treatment of an aneurysm of a distal branch of the renal artery. Ann Vasc Surg 2014; 28:260.e9-e12. [CrossRef]

22. Gandini $R$, Spinelli A, Pampana E, Fabiano $S$, Pendenza G, Simonetti G. Bilateral renal artery aneurysm: percutaneous treatment with stentgraft placement. Cardiovasc Intervent Radiol 2006; 29:875-878. [CrossRef]

23. Sahin S, Okbay M, Cinar B, Uzunlul N. Widenecked renal artery aneurysm: endovascular treatment with stent-graft. Diagn Interv Radiol 2007; 13:42-45.

24. Centenera LV, Hirsch JA, Choi IS, Beckman CF, Gillard CS, Libertino J. Wide-necked saccular renal artery aneurysm: endovascular embolization with the Guglielmi detachable coil and temporary balloon occlusion of the aneurysm neck. J Vasc Interv Radiol 1998; 9:513-516. [CrossRef]

25. Mounayer C, Aymard A, Saint-Maurice JP, Chapot R, Merland JJ, Houdart E. Balloon-assisted coil embolization for large-necked renal artery aneurysms. Cardiovasc Intervent Radiol 2000; 23:228-230. [CrossRef]

26. Dib M, Sedat J, Raffaelli C, Petit I, Robertson WG, Jaeger P. Endovascular treatment of a wide-neck renal artery bifurcation aneurysm. J Vasc Interv Radiol 2003; 14:1461-1464. [CrossRef]

27. Ikeda O, Tamura Y, Nakasone Y, Iryou Y, Yamashita $Y$. Nonoperative management of unruptured visceral artery aneurysms: treatment by transcatheter coil embolization. J Vasc Surg 2008; 47:1212-1219. [CrossRef]

28. Bratby MJ, Lehmann ED, Bottomley J, et al. Endovascular embolization of visceral artery aneurysms with ethylene-vinyl alcohol (Onyx): a case series. Cardiovasc Intervent Radiol 2006; 29:1125-1128. [CrossRef]

29. Manninen HI, Berg M, Vanninen RL. Stent assisted coil embolisation of wide necked renal artery bifurcation aneurysms. J Vasc Interv Radiol 2008; 19:487-492. [CrossRef]

30. Lupattelli T, Abubacker Z, Morgan R, Belli AM. Embolization of a renal artery aneurysm using ethylene vinyl alcohol copolymer (Onyx). J Endovasc Ther 2003; 10:366-370. [CrossRef]

31. Rautio R, Haapanen A. Transcatheter embolization of a renal artery aneurysm using ethylene vinyl alcohol copolymer. Cardiovasc Intervent Radiol 2007; 30:300-303. [CrossRef]

32. Abath C, Andrade G, Cavalcanti D, Brito N, Marques R. Complex renal artery aneurysms: liquids or coils? Tech Vasc Interv Radiol 2007; 10:299-307. [CrossRef]

33. Künzle S, Glenck M, Puippe G, Schadde E, Mayer $D$, Pfammatter T. Stent graft repairs of visceral and renal artery aneuryms are effective and result in long term patency. J Vasc Interv Radiol 2013; 24:989-996. [CrossRef] 
34. Peynircioglu B, Ergun O, Hazirolan T, et al. Stent-graft applications in peripheral non atherosclerotic arterial lesions. Diagn Interv Radiol 2008; 14:40-50.

35. Laganá D, Carrafiello G, Mangini M, et al. Emergency percutaneous treatment of arterial iliac axis ruptures. Emerg Radiol 2007; 14:173-179. [CrossRef]

36. lerardi AM, Kehagias E, Piffaretti G, et al. ePTFE stent graft in non-steno-occlusive arterial disease: 2 centers retrospective study. Radiol Med 2016; 121:482-493. [CrossRef]

37. Bracaie UM, Narese D, Ficarelli I, et al. Stent-assisted detachable coil embolization of widenecked renal artery aneurysms. Diagn Interv Radiol 2017; 23:77-80. [CrossRef]

38. Meyer C, Verrel F, Weyer G, Wilhelm K. Endovascular management of complex renal artery aneurysms using the multilayer stent. Cardiovasc Intervent Radiol 2011; 34:637-641. [CrossRef]

39. Henry M, Polydorou A, Frid N, et al. Treatment of renal artery aneurysm with the multilayer stent. J Endovasc Ther 2008; 15:231-236. [CrossRef]
40. Wojtassek M. Managing visceral artery aneurysms. Endovascular Today 2013; 77-81.

41. Sfyroeras G, Dalainas I, Giannakopoulos TG, Antonopoulos K, Kakisis J, Liapis CD. Flow- diverting stents for the treatment of arterial aneurysms. $J$ Vasc Surg 2012; 56:839-846. [CrossRef]

42. Ruffino M, Rabbia C. Endovascular treatment of visceral artery aneurysms with Cardiatis multilayer flow modulator: preliminary results at sixmonth follow-up. J Cardiovasc Surg (Torino) 2011; 52:311-321.

43. Abraham RJ, Illyas AJ, Marotta T, Casey P, Vair B, Berry R. Endovascular exclusion of a splenic artery aneurysm using a pipeline embolization device. $J$ Vasc Interv Radiol 2012; 23:131-135. [CrossRef]

44. Shlomovitz E, Jaskolka JD, Tan KT. Use of a flow-diverting uncovered stent for the treatment of a superior mesenteric artery aneurysm. J Vasc Interv Radiol 2011; 22:1052-1055. [CrossRef]

45. Bhogal $P$, Ganslandt $O$, Bäzner $H$, Henkes $H$, Pérez MA. The fate of side branches covered by flow diverters- results from 140 patients. World Neurosurg 2017; 103:789-798. [CrossRef]
46. Kulcsár Z, Ernemann U, Wetzel SG, et al. High-profile flow diverter (silk) implantation in the basilar artery: efficacy in the treatment of aneurysms and the role of the perforators. Stroke 2010; 41:1690-1696. [CrossRef]

47. Becske T, Brinjikji W, Potts MB, et al. Long-term clinical and angiographic outcomes following pipeline embolization device treatment of complex internal carotid artery aneurysms: five-year results of the pipeline for uncoilable or failed aneurysms trial. Neurosurgery 2017; 80:40-48.

48. Rouchaud A, Leclerc O, Benayoun $\mathrm{Y}$, et al. Visual outcomes with flow-diverter stents covering the ophthalmic artery for treatment of internal carotid artery aneurysms. AJNR Am J Neuroradiol 2015; 36:330-336. [CrossRef]

49. Fahed R, Gentric JC, Salazkin I, Gevry G, Raymond J, Darsaut TE. Flow diversion of bifurcation aneurysms is more effective when the jailed branch is occluded: an experimental study in a novel canine model. J Neurointerv Surg 2017; 9:311-315. [CrossRef] 